\title{
An Integrative Approach for Determining Consumers Mobile Advertising Related Attitudes and Intentions
}

\author{
https://doi.org/10.3991/ijim.v14i15.14955
}

\author{
Ghazanfar. A. Abbasi $\left.{ }^{\bowtie}\right)$, Su-Yee Sea, Goh Yen-Nee \\ Universiti Sains Malaysia, George Town, Malaysia \\ ghazanfar.abbasi@hotmail.co.uk
}

\begin{abstract}
The purpose of this paper is to propose and test an integrated model of mobile advertising taking into consideration the exclusive characteristics of Malaysian consumers. The survey research method has been used to collect data among young mobile users in Malaysia. A partial least squares structural equation model (PLS-SEM) technique is employed to analyze the data. The results show that perceived usefulness, perceived ease of ease, irritation, entertainment, and credibility emerge as significant belief factors positively influencing attitude in of Malaysian consumers. Irritation, on the other hand, negatively predicts attitude. Attitude toward mobile advertising and subjective norm emerge as the strong predictors of the consumers' intention to purchase products and services as advertised in mobile advertising. The findings are particularly relevant to international marketing managers. To effectively reach Asian consumers through mobile, increasing credibility, perceived ease of use, perceived usefulness, subjective norm and entertainment values are the keys. Based on the established advertising theories, this study proposes an integrated model to examine how users' attitude and social factor affect mobile advertising effectiveness among Malaysian consumers. This research provides insights into the effectiveness and of the novel mobile medium as compared to orthodox mediums. Also, this study excavates the understanding of advertising hierarchy effects in an international setting by examining the importance of each variable in an emerging Asia-Pacific country like Malaysia. The study answers such a call.
\end{abstract}

Keywords - Perceived usefulness, perceives ease of use, credibility, entertainment, informativeness, irritation, Malaysia.

\section{Introduction}

Mobile communications have relished a remarkable development around the world over the last ten years [1]. It is estimated that there were more than 7 billion mobile subscription resulting to $95 \%$ of world population [2]. The ever-rising penetration rate coupled with exclusive characteristics, mobile devices are becoming an efficient and effective medium for advertisement [3]. The entire fraternity of advertising has been extraordinarily revamped by the growth in the digital technologies [4]. Besides, the mounting acceptance of devices like tablets and smartphones and spread of applications also helped to fuel a jump in the mobile advertising market [5]. According to the reports 
it is evident that digital advertising is the most prominent and substantial cause in the growth of media advertising spend ("ad spend") [5]. According to e-Marketer [6] the revenue generated in 2017 was estimated to be about US\$228.4 billion, which is further forecasted to be US\$375.8 billion at the end of 2021, representing to $49.6 \%$ of total ad spend. Despite the speedy evolution of mobile communications universally and snowballing adoption of mobile advertising in international businesses, very few studies have examined mobile advertising effectiveness from the global marketing perspective. The present study is designed to investigate mobile advertising in emerging country in Asia-Pacific i.e. Malaysia. Specifically, the present research examines how beliefs, attitude and other influencing factors affect mobile advertising effectiveness among Malaysian Consumers.

Considering the progress of mobile ad spend is the swift penetration of mobile devices - mobile phones in particular - and the openings that such devices offer companies to send highly tailored and personalized marketing messages to their consumers $[1,7]$. This method for consumers receiving marketing information from mobile channels is labelled as mobile marketing $[4,8]$. There is no doubt that mobile commerce market is seeing fierce competitions in regard to retaining and attracting customers, subsequently, driving companies to plan an indispensable marketing strategy [9]. Mobile advertising is the most significant strategy of mobile marketing for upholding competitiveness in the market. Whereas, mobile advertising is a type of online advertising especially designed for users of smart devices like mobiles and tablets [10]. Designers of mobile advertisement can plan and strategize to take advantage of mobile advertising to attain greater effect and increase their target reach.

Prior literature has already established theories in marketing such as the theory of reasoned action (TRA) [11] and the theory of planned behavior (TPB) [12] which posit that belief factors affect consumers' attitude toward advertising has a significant effect on users' behaviours. Venkatesh and Davis (2000) developed technology acceptance model (TAM) on the basis of earlier model theory of reasoned action (TRA) and applied to investigate new and novel technologies/medium approach. Venkatesh and Davis [13] TAM model consists of two main belief factors: perceived ease of use (PEOU) and perceived usefulness (PU). This research aims to investigate users' attitude towards mobile advertising in an emerging Asian-Pacific country like Malaysia, researches of this study used an integrative approach by integrating TAM and Ducoffe's web advertising model to achieve the aim of the study, as proposed by earlier researchers [14]. Therefore, fulfilling the potential research gap, the current study proposes and tests a novel research model that integrates TAM and Web Advertising Model $[15,16]$ to investigate Malaysian users' attitude towards mobile advertising and their effects on their purchase intention. Research has shown that an integrative model reinforces the significance and predictability of the results $[17,18]$. Furthermore, while there is growing interest in digital advertising in general, research in the area is still in its infancy, and there is little clear understanding of the factors that influence the effectiveness of model advertising policies [19].

Theoretically, this study makes several contributions to the mobile advertising research: firstly, mobile advertisement unlike traditional old mediums is considered as a 
novel approach and address the challenges of validity of earlier studies for its effectiveness. The advancement of TAM warrants such investigation. The earlier studies have applied the TAM model in the quest to examine new technologies without pay a due attention to specific medium such as mobile advertisement. Therefore, to achieve the nitty gritty of this medium, the researcher has chosen to apply TAM along with Ducoffe's web advertising model. Given the fact that the mobile medium is highly personal and interactive, factors such as informativeness, irritation, credibility and entertainment concerns may become striking influencing variables to shape users attitude towards mobile advertising. Therefore, in this study, our research model includes not only the key variables proposed in TRA and TAM, but also the important variables identified by past research that are particularly relevant in the mobile advertising context to examine the relationships among influencing factors and mobile advertising effectiveness. Secondly, by focusing on consumers from an emerging economy - Malaysia - this study provides a valuable extension to the extant body of knowledge relating to digital advertising from a contextual viewpoint. Most existing studies on mobile advertising are grounded on samples drawn from developed economies i.e. US, China etc. Very scant attention has been paid precisely to developing and directing mobile marketing strategies in the Asia-Pacific context. This research makes noteworthy contributions to the understanding of what and how several factors persuading the effectiveness of mobile advertising that are particular to Asia-Pacific consumers. Therefore, this study fills this potential gap in mobile advertising literature and provides empirical support for Ducoffe's and TAM in the sense that these theories can be successfully applied and validated in Asia-Pacific cultures as well. The element of cultural differences between countries can significantly the extent to which findings from one country, may apply to another, due to differences in cultural values, among other factors [20].

From the standpoint of practical contribution, this research is meaningful for both organizations and business operating globally which seek to influence and reach Asian consumers via mobile devices. As suspicion and lack of trust regarding advertising and marketing efforts increases on gradual basis, it is utmost pivotal for global marketers to unearth innovative and novel ways to communicate with global consumers. Mobile is an ever evolving and swift-growing advertising medium and has all the ingredients to become a powerful promotional device if used in the right way. In lieu of soaring importance of Asian market in the global economy, this study offers much needed insights for marketers to target Asian consumers using mobile tools.

\section{$2 \quad$ Literature Review}

\subsection{Empirical studies on mobile advertisement}

Researchers across the globe have conducted several studies in order to understand consumers' attitudes toward mobile advertising. In China for example, Zang et al. [21] conducted a study and empirically established that entertainment, credibility, and personalisation of mobile advertising were positively related to consumers' attitudes to- 
ward mobile advertising while irritation was negatively related to attitudes toward mobile advertising. Similarly, in an online-based study, Hsiao and Chang [22] demonstrated that perceived value, perceived usefulness, and satisfaction of consumers were critical in consumers' continuance intention to receive mobile advertisements. More recently, Martínez-Ruiz et al. [23] also corroborated the importance of perceived usefulness in engendering positive attitudes toward mobile advertising in Spain. Besides, Lin and Bautista [4] also investigated the impact of content related factors on location based mobile advertising and empirically discovered that credibility, entertainment, irritation had a significant effect on the perceived value of mobile advertising. As is evident from the foregoing researches, consumers' attitudes toward mobile advertising is determined by both web advertising model and TAM related factors such as credibility, entertainment, irritation, informativeness, perceived usefulness and perceived ease of use. However, owing to attain the parsimony, prior research has not been holistically investigating the integrative effect of TAM and web advertising model, therefore, the present study attempts to readdress this imbalance by focusing on integrated model to investigate both users' attitudes towards mobile advertising and their purchase intention.

\subsection{Technology Acceptance Model (TAM)}

Technology Acceptance Model (TAM) introduced by Davis (1985). Its theoretical background originates from TRA [24]. The purpose of TAM is to explain on the determinants of computer acceptance and user behaviour across end-user computing technologies. It provides a basis for tracing the impact of external factors on internal beliefs, attitudes, and intentions [25]. Most of the past researches of users' adoption a technologically based innovation has employed TAM framework, which is based on two elements: perceived ease of use and perceive usefulness [26, 27, 28]. These two elements are predictive of intentions of technology adoption [25]. Subsequently, researchers applied TAM in the study of mobile marketing and advertising as computing technologies are the channel of marketing. Thereby, this study applies TAM for the purpose of investigating the factors of consumers' attitudes and behaviour on perceiving usefulness and ease of use of mobile devices [29, 10].

\subsection{Ducoffe's web advertising model}

Ducoffe [15] developed an approach to study the effectiveness of attitude toward web advertising. This model consists of three elements, namely, informativeness, entertainment and irritation. Thereafter, Brackett and Carr [16] enhanced the original model by adding two elements in this model, which are credibility and relevant demographic variables. Web advertising model has applied in most of the web advertising studies $[15,16,10,23]$. This study applies web advertising model due to many advertisements, promotions and offers messages transmitted via mobile devices with Internet access. Nowadays, SMS advertising [30,31] is not the only channel which is commonly used. Many advertisements also transmit via application software (apps) which installed in smart phones or tablet PC $[14,32,33]$ by using non-fixed network. As the earlier 
research by Tsang et al. [3] found that this model is suitable to test in the study of mobile advertising.

\section{Hypotheses Development}

\subsection{Technology related factors}

Both perceived ease of use (PEOU) and perceived usefulness (PU) has been the epicentre of research specially in technology adoption related literature [26, 27, 28, 24]. PU refers to individual's evaluation of the utilities offered by the technology, whereas, PEOU refers to the degree of required effort that is needed to take advantage of a new technology [5]. In a cross-culture study by Wang and Genc [5] it was empirically posited that both Taiwan and Chinese consumers' attitude toward mobile advertising was influenced by perceived usefulness and perceived ease of use. Similar results were attained by Bakar and Bidin [34] on Malaysia consumers, Muk and Chung [31] on Korean and American consumers. Therefore, it can be implied that users are more likely to accept a technology that is perceived to be easier to use than another. Thus, the above discussion has led to the making of following hypotheses:

- H1: Perceived usefulness has positive influences on consumer' attitudes toward mobile advertising.

- H2: Perceived ease of use has positive influences on consumers' attitudes toward mobile advertising.

- H3: Perceived ease of use has a positive influence on users perceived usefulness.

\subsection{Ducoffe's web advertising related factors}

Ducoffe [15] introduced informativeness in web advertising model to test on the advertising value. Most consumers perceived advertisements on web is informative and create advertising value, hence, positively affect their attitudes toward web advertising [15] In our context, information dimension related to an advertisement, which is usually referred to as 'informativeness', is accepted as one of the noteworthy factors creating value for the consumers and affecting their attitudes towards advertisements [35, 33, 30]. Aydin and Karamehmet [35] stated that provision of information, information quality characteristics, such as correctness, timeliness, and usefulness are the main and important function of advertising. Moreover, Lee et al. [33] found that informativeness of advertising through mobile devices such as cell phones and personal digital assistant (PDA) is important and significantly influences consumers' attitudes. In other words, advertising provides product-related and timely information is important to consumers and it creates advertising value, subsequently affecting their attitude towards mobile advertisement $[15,16,33]$. Thus, the above discussion articulated following hypothesis:

- H4: Users attitude towards mobile advertisement is positively influenced by their perception of mobile advertisement as informative. 
The entertainment dimension of advertisements is considered as one of the major factors affecting attitudes towards and acceptance of advertisements [4, 35]. This dimension is related to the enjoyment that is associated with the advertisement itself. Consumers usually develop a positive attitude towards messages that they find advertisement entertaining $[5,35]$. Consequently, this effect/relationship found in traditional advertising is expected to be present in the mobile advertising context. Various researchers have included entertainment dimension in their studies and detected positive effects of entertainment on attitude towards mobile marketing activities [5, 35]. Thus, it can be implied that if the users receiving the mobile advertisement perceive it as entertaining, it is highly likely to develop a positive attitude towards mobile advertising Therefore, the following discussion led to the making of following hypothesis:

- H5: Users attitude towards mobile advertisement is positively influenced by their perception of mobile advertisement as entertaining.

Prior marketing research has identified irritation as a negative belief factor influencing attitudes toward advertising [4, 5]. Given the personal and private nature of the mobile medium, irritation may be a more salient factor in mobile advertising context than that of traditional media. Lin and Bautista [4] in their empirical study established that irritation negatively affects users towards mobile advertising. Wang and Genc [5] identified six variables affecting the users' attitude towards mobile advertising among millennials including perceived entertainment usefulness, perceived information usefulness, perceived social usefulness, irritation, credibility, and ease of use. They found that users are more likely to adopt mobile advertising if it is not irritating. Past studies have shown that negative consequences such as poor attitude toward web advertisements arise from irritating online advertisements $[4,5]$ Thus, we propose the following hypothesis:

- H6: Users attitude towards mobile advertisement is negatively influenced by their perception of mobile advertisement as irritating.

Among the primary factors affecting attitude towards advertisements in the literature is found to be credibility. Advertising credibility has been defined as one's beliefs about the integrity, truthfulness, and honesty, of an advertisement [4]. Studies have found that credibility positively influences consumers' attitude toward advertising [5, 35]. Specifically, Lin et al. [10] examined the relationships among beliefs, attitude and consumer responses in online advertising and found that credibility is one of the significant belief factors that positively affect attitude toward online advertising. Therefore, we propose the following hypothesis:

- H7: Users attitude towards mobile advertisement is positively influenced by their perception of mobile advertisement as credible.

Many studies have indicated that attitude can directly affect intention. For example, the TAM by Davis (1989) and advertising evaluation by Wang and Genc [5], MartínezRuiz et al. [23] and Lin et al. [10] have indicated the positive relationship between attitude towards the model advertisement and user's intention. Hausman and Siekpe 
[36] argued that attitude can affect purchase intention. Similar results were achieved by

[47]. Based on the above, this study proposes the following hypothesis:

- H8: Consumers' attitudes toward mobile advertising positively influence the consumers' intention to purchase products and services as advertised in mobile advertising.

\subsection{Social factor: Subjective norm}

Subjective norm has been used to study the relevance of social context in influencing behavioural intention. Specifically, subjective norm refers to the extent to which an individual believes that people who are important or influential to him or her think he or she should perform the behavior in question (Fishbein and Ajzen, 1975). Subjective norm has been included in mobile advertising research. Richard and Meuli [37], for example, found that subjective norm significantly and positively influences Millennials' intention of using permission-based mobile advertising. Similar results were attained by cross cultural study by Wang and Genc [5] and empirically established that subjective norms have a positive effect on consumer's intention towards mobile advertising. Thus, this leads to the making of following hypothesis:

- H9: Subjective norms positively influence the consumers' intention to purchase products and services as advertised in mobile advertising.

\section{Methodology}

\subsection{Measurement}

The survey items used were adopted from past studies and were slightly modified to fit the context of this study. All items were measured using a Likert scale where respondents selected 1 for "strongly disagree" to 5 for "strongly agree". Perceived usefulness $(M=3.95, S D=0.94)$, Perceived ease of use $(M=3.79, S D=0.62)$ and attitude towards mobile advertising (ATT) $(\mathrm{M}=3.11, \mathrm{SD}=0.86)$ was measured with three, three and four items from adapted by Yang et al. [14] respectively. The measurement items for entertainment $(\mathrm{ENT})(\mathrm{M}=3.28, \mathrm{SD}=0.96)$ and irritation (IRR) $(\mathrm{M}=2.97$, $\mathrm{SD}=0.93$ ) four items each are adapted from Ducoffe's [15]. Informativeness (INF) (M $=3.65, \mathrm{SD}=0.77$ ) with four items is measured from Ducoffe [15] and Kim and Han [32]. Items for subjective norm $(\mathrm{SN})(\mathrm{M}=2.99, \mathrm{SD}=0.74)$ and purchase intention (PI) $(\mathrm{M}=3.02, \mathrm{SD}=0.81)$ are adopted from Noor et al. [38]. Credibility (CRE) was assessed by four measurement items by Liu et al. [39].

\subsection{Procedure and sampling}

The present cross-sectional study aimed at examining the attitude and the behaviour related to mobile advertising of Malaysian consumers. The proposed hypotheses were 
tested using a quantitative research approach. An online survey containing 32 questions was used for the empirical collection of data. To cater common method bias, the researcher applied procedural techniques as suggested by Podsakoff et al. [40]. Also, a non-probabilistic and self-selection sampling method (i.e. convenience sampling) was employed in this research to collect data from the potential participants based on their availability. The data collection took place in the biggest shopping malls of the city. At respondent's approval, the link of the online survey was sent to them via email. The online survey comprised of a cover letter explaining the aim of the study and participants rights in participating. No financial incentive or rewards in kind was offered. A total of 300 questionnaires were sent and the study received a response rate of $41.33 \%$ which is deemed appropriate especially in online related studies.

\section{$5 \quad$ Data Analysis}

This study used Partial Least Squares (PLS) for data analysis as it has gained popularity and is frequently used in marketing and business-related studies [41]. As a fullfledged structural equation modelling (SEM) technique, PLS allows simultaneous analysis of multiple independent and dependent variables in a complex research model that is not possible in typical regression analyses [41]. In this research, SmartPLS 3.2.9 was used to perform PLS for the data analysis. Moreover, SPSS was used for descriptive analysis.

\section{$6 \quad$ Results}

\subsection{Assessment of measurement model}

This study measures the inner model (validity and reliability of the constructs, factor loadings, composite reliability (CR), average variance extracted (AVE), and the hetrotrait-monotrait ratio (HTMT)) as per Hair et al. [41] instructions. The results of the inner model can be seen in Table 1. Conferring to the results, factor loadings, CR, and AVE are above $0.7,0.7$, and 0.5 , respectively [41]. Therefore, the convergent validity of all the constructs was established. Besides convergent validity, the current study also examined the discriminant validity of the outer model by applying HTMT criteria as suggested by Henseler et al. [42]. As all HTMT values were lower than 0.85 (see Table 3 ); hence, no issues pertaining to discriminant validity were not found in this study [42] see Table 1 and Table 2. Thus, measurement model validation as achieved satisfactorily. 
Paper-An Integrative Approach for Determining Consumers Mobile Advertising Related Attitudes...

Table 1. PLS Result of Convergent Validity Measures

\begin{tabular}{|c|c|c|c|c|}
\hline Latent Variable & Measurement Item & Loading & $\mathbf{C R}$ & AVE \\
\hline \multirow{3}{*}{ Perceived Usefulness } & U1 & 0.794 & \multirow{3}{*}{0.845} & \multirow{3}{*}{0.645} \\
\hline & $\mathrm{U} 2$ & 0.828 & & \\
\hline & $\mathrm{U} 3$ & 0.787 & & \\
\hline \multirow{3}{*}{ Perceived Ease of Use } & EOU1 & 0.735 & \multirow{3}{*}{0.841} & \multirow{3}{*}{0.640} \\
\hline & EOU2 & 0.767 & & \\
\hline & EOU3 & 0.889 & & \\
\hline \multirow{4}{*}{ Informativeness } & IN1 & 0.837 & \multirow{4}{*}{0.927} & \multirow{4}{*}{0.760} \\
\hline & IN2 & 0.885 & & \\
\hline & IN3 & 0.880 & & \\
\hline & IN4 & 0.884 & & \\
\hline \multirow{4}{*}{ Entertainment } & EN1 & 0.934 & \multirow{4}{*}{0.970} & \multirow{4}{*}{0.889} \\
\hline & EN2 & 0.938 & & \\
\hline & EN3 & 0.958 & & \\
\hline & EN4 & 0.942 & & \\
\hline \multirow{4}{*}{ Irritation } & IR1 & 0.938 & \multirow{4}{*}{0.942} & \multirow{4}{*}{0.804} \\
\hline & IR2 & 0.930 & & \\
\hline & IR3 & 0.832 & & \\
\hline & IR4 & 0.883 & & \\
\hline \multirow{3}{*}{ Credibility } & CR1 & 0.831 & \multirow{3}{*}{0.911} & \multirow{3}{*}{0.773} \\
\hline & $\mathrm{CR} 2$ & 0.902 & & \\
\hline & CR3 & 0.903 & & \\
\hline \multirow{4}{*}{ Attitude } & ATT1 & 0.902 & \multirow{4}{*}{0.952} & \multirow{4}{*}{0.833} \\
\hline & ATT2 & 0.926 & & \\
\hline & ATT3 & 0.925 & & \\
\hline & ATT4 & 0.896 & & \\
\hline \multirow{3}{*}{ Subjective Norm } & SN1 & 0.872 & \multirow{3}{*}{0.874} & \multirow{3}{*}{0.700} \\
\hline & SN2 & 0.869 & & \\
\hline & SN3 & 0.763 & & \\
\hline \multirow{4}{*}{ Purchase Intention } & PI1 & 0.836 & \multirow{4}{*}{0.891} & \multirow{4}{*}{0.672} \\
\hline & $\mathrm{PI} 2$ & 0.860 & & \\
\hline & PI3 & 0.696 & & \\
\hline & PI4 & 0.876 & & \\
\hline
\end{tabular}

Table 2. Discriminant Validity: HTMT Criterion

\begin{tabular}{|c|c|c|c|c|c|c|c|c|c|}
\hline & 点 & 空 & 㫐 & 至 & $\Xi$ & 吕 & $\begin{array}{l}0 \\
0 \\
\text { 됨 }\end{array}$ & Q & Z \\
\hline \multicolumn{10}{|l|}{ ATT } \\
\hline CRE & 0.803 & & & & & & & & \\
\hline ENT & 0.78 & 0.76 & & & & & & & \\
\hline INF & 0.632 & 0.633 & 0.78 & & & & & & \\
\hline PI & 0.785 & 0.704 & 0.642 & 0.499 & & & & & \\
\hline IRR & 0.653 & 0.518 & 0.581 & 0.385 & 0.356 & & & & \\
\hline PEOU & 0.673 & 0.595 & 0.515 & 0.474 & 0.634 & 0.414 & & & \\
\hline $\mathrm{PU}$ & 0.696 & 0.676 & 0.749 & 0.837 & 0.573 & 0.408 & 0.506 & & \\
\hline $\mathrm{SN}$ & 0.395 & 0.341 & 0.478 & 0.677 & 0.498 & 0.19 & 0.387 & 0.667 & \\
\hline
\end{tabular}




\subsection{Assessment of structural model}

After meeting the measurement model criteria, this study tested the hypotheses using the structural model. To check the significance of the hypotheses, a nonparametric bootstrapping process with 5000 iterations was employed [41]. Current study statistical results supported the conceptual model via explaining $71.5 \%, 52.8 \%$ and $14.9 \%$ of the variance in users' attitude towards mobile advertising, intention to purchase and their perceived usefulness. In addition to R2, the current study also examined the effect size (f2) as per the guidelines of Cohen [43], see Table 3. To investigate the predictive relevance of the path models used in the study, the researcher applied Stone and Geisser's (Q2). According to the results, the Q2 for all the endogenous constructs are above the zero [44] i.e. PI (0.344), ATT (0.586) and PU (0.089). Furthermore, the results of the significant path coefficient, R2 and the effect size can be seen from Table 3.

Table 3. Path Co-efficient and Hypothesis Testing

\begin{tabular}{|l|c|c|c|l|c|c|}
\hline Hypothesis & Beta & T-stats & P-value & Decision & $\mathbf{f}^{2}$ & VIF \\
\hline H1 & 0.119 & 11.466 & $0 * * *$ & Supported & 0.025 & 1.987 \\
\hline H2 & 0.205 & 3.292 & $0.001^{* * *}$ & Supported & 0.105 & 1.403 \\
\hline H3 & 0.386 & 5.714 & $0 * * *$ & Supported & 0.175 & 1.000 \\
\hline H4 & 0.005 & 0.071 & 0.472 & Not Supported & 0.000 & 2.518 \\
\hline H5 & 0.253 & 2.592 & $0.005^{* * *}$ & Supported & 0.068 & 3.316 \\
\hline H6 & -0.231 & 3.88 & $0^{* * *}$ & Supported & 0.125 & 1.500 \\
\hline H7 & 0.272 & 3.608 & $0^{* * *}$ & Supported & 0.122 & .119 \\
\hline H8 & 0.627 & 11.466 & $0^{* * *}$ & Supported & 0.713 & 1.165 \\
\hline H9 & 0.201 & 3.044 & $0.001^{* * *}$ & Supported & 0.073 & 1.165 \\
\hline
\end{tabular}

Note: $* * \mathrm{p}<0.05, * * * \mathrm{p}<0.01$

\subsection{Importance Performance Map Analysis (IPMA)}

Current study further performed IPMA to list down the importance and performance of the latent constructs used in this research for endogenous variable i.e. attitude towards the mobile advertising only. Figure 1 shows the level of importance on horizontal axis and the percentage of performance on the vertical axis with cumulative values of 0.1275 and $56.83 \%$ respectively. PU was the highest performing construct with the values of $71.31 \% \%$ followed by informativeness and entertainment with values $63.04 \%$ and $57.12 \%$ respectively whereas, both PEOU and irritation was found among the lowest of all with $49.7 \%$ and $49.5 \%$ value. Following the Leong et al. [45] and Ooi et al. [46], researchers also segregated into four quadrants with quadrant 1 on the upper-right corner, quadrant 2 on the lower-right corner, quadrant 3 on the lower left side and quadrant 4 on the upper-left corner. From these quadrants' emphasis must be provided to the quadrant 2 constructs (CRE and PEOU) since these constructs are highly imperative but gives lower performance followed by quadrant 1,3 and 4 . 


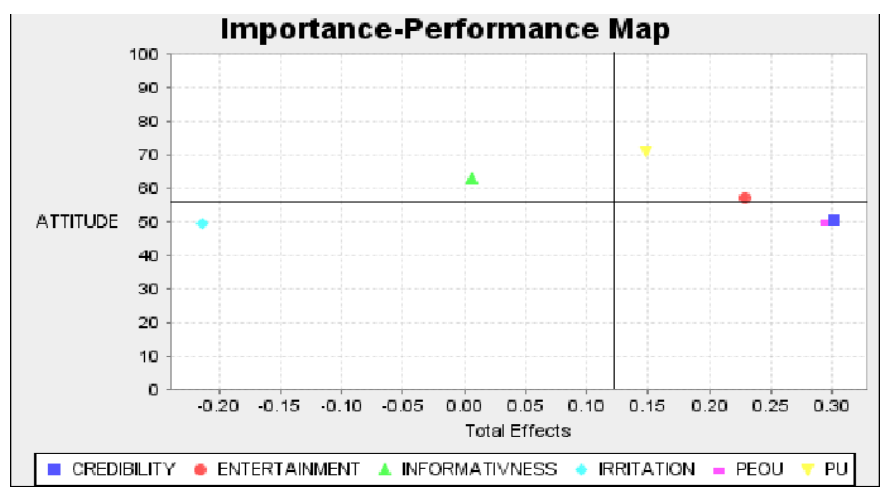

Fig. 1. IPMA analysis

\section{$7 \quad$ Discussion}

Taking an integrative perspective, this study has shed noteworthy importance on factors that contribute to the influence of mobile advertising on consumers' attitudes and how such attitudes and subjective norm affect customers' purchase intention. Consistent with the original idea of Davis et al. [25] this study findings reveal that both PU and PEOU has a positive and significant effect on users' attitudes towards mobile advertising. The current study also investigated the Ducoffe's web advertising model with four factors and empirically validated that credibility, irritation and entertainment has significant effect on users' attitude towards mobile advertising except informativeness which was found to have no significant effect. Furthermore, the study also revealed that both attitude towards mobile advertising and subjective norm has positive and significant on consumers' intention to purchase products and services as advertised in mobile advertising.

Findings of the study reveal that both PU and PEOU was found to have positive and significant effect on users' attitude towards mobile advertising, hence $\mathrm{H} 1$ and $\mathrm{H} 2$ were supported. These results are in line with the previous researchers such as $[4,5]$. Our study also revealed that PEOU has a positive and significant effect on PU, thus, H3 was also supported. The results of this study imply that if the recipients of mobile advertisement find mobile advertising as useful and ease of use, they are likely to have a positive attitude towards it. From the Ducoffe's web advertising model, both credibility and entertainment are found to have the strongest and significant impact on users' attitude, therefore, $\mathrm{H} 5$ and $\mathrm{H} 7$ are supported. the findings of the study imply that when consumers perceive mobile advertising messages and sources as trustworthy, they are highly expected to have a favorable attitude towards mobile advertising. Findings of this study are consistent with previous research, which has found that both entertainment and credibility positively influences attitudes toward advertising $[4,5]$. Especially, factor like entertainment becomes more vital and relevant in high context culture like Malaysia, because people are more likely to use mobile advertising to satisfy their hedonic and emotional needs and desire an entertainment and emotional driven advertising approach. 
Also, irritation emerged as a negative factor influencing users' attitude towards mobile advertisement, thus, H6, was supported. The negative effect of irritation especially in similar context was in line with earlier extant researches by [4, 5]/ The result implies that as mobile phones are regarded as very private, users will develop a negative attitude if they believe mobile advertising is irritating [3]. Informativeness was found to have no effect on users' attitude towards mobile advertisement, thus, H4 was not supported. This is contradictory to the results of [5]/ The findings of the study reveal that if the information in the advertisement is perceived as relevant, timely, accurate and trustworthy, the users may not develop a positive attitude towards it. In addition to the above factors, both attitude and subjective norm was found to have positive and significant effect on consumers' intention to purchase products and services as advertised in mobile advertising, thus $\mathrm{H} 8$ and $\mathrm{H} 9$ both are supported. This is line with the previous research $[4,5,10]$. As Malaysia is typical collective culture, peer influence in the form of subjective norm is possibly to have more influence on consumers' decision-making process in collectivist cultures as compared to people in individualistic cultures.

There is no doubt that penetration rate of mobile globally has increased with leaps and bounds and mobile phone as become an integral part of human lives. Advertising business all across the globe are emphasizing on mobile phones as medium for commercial purposes to develop and orchestrate new advertising platforms. Owing to the relative low cost involved in mobile advertising as compared to other forms of mediums. Moreover, these mobile phones are evolving 24/7 in respect to their size and their capability to perform as task. Recognizing the main aspects that can influence the attitude towards mobile advertising will not only contribute to the promotion of mobile advertising and plan but also deliver a reference for the future development of mobile advertising. These results draw some potential road map for future strategist while planning mobile advertising such as the mobile advertising industry should predominantly note whether users are impartial in the mobile advertising. There could be several reasons why users develop not a positive attitude towards mobile advertising such as either the information is too much, it's irrelevant, not timely etc. Mobile advertising industry must amass valuable information to plan mobile advertisement for users in a right way and at the right time. Furthermore, it should make the user feel that receiving mobile advertising is useful. It can become a source to attract users for consumption. Also, the designers of mobile advertisement should pay more effort on user readiness to receive mobile advertising. Moreover, mobile advertising must be perceived as being easy to use. The findings of this research can prove to be a steppingstone to make note of all the above suggestion and factors while designing the mobile advertisement. Thus, it can be said that if the mobile advertising industry can orchestrate mobile advertising as per the above recommendations, it is believed that user purchase intention can be boosted.

\section{$8 \quad$ Limitations and Future Recommendations}

This study aimed to examine how attitude and social factor like subjective norm affect mobile advertising in an important Asia-Pacific market of Malaysia. Overall, we 
found that users factors like credibility, entertainment, irritation, perceived ease of use, perceived usefulness about mobile advertising significantly influence users' attitude towards mobile advertising, which in turn positively and significantly influences consumers' intention. These results are consistent with previous research and provide additional empirical support for the theories of TAM and Ducoffe's web advertising model in the mobile advertising context.

\section{$9 \quad$ References}

[1] Mpinganjira, Mercy, and Daniel K. Maduku. "Ethics of mobile behavioral advertising: Antecedents and outcomes of perceived ethical value of advertised brands." Journal of Business Research vol. 95, pp 464-478, 2019. https://doi.org/10.1016/j.jbusres.2018.07.037

[2] International Telecommunication Union, "ITU releases 2017 global information and technology facts and figures" 2017. [online]. Available https://news.itu.int/itu-releases-2017global-information-and-communication-technology-facts-and-figures/ [Accessed 2nd Feb 2020]. https://doi.org/10.3233/gov-130336

[3] Tsang, Melody M., Shu-Chun Ho, and Ting-Peng Liang. "Consumer attitudes toward mobile advertising: An empirical study." International journal of electronic commerce vol. 8, no. 3, pp. 65-78, 2004. https://doi.org/10.1080/10864415.2004.11044301

[4] Lin, Trisha TC, and John Robert Bautista. "Content-related factors influence perceived value of location-based mobile advertising." Journal of Computer Information Systems vol. 60, no. 2, pp. 184-193, 2020. https://doi.org/10.1080/08874417.2018.1432995

[5] Wang, Ying, and Ebru Genç. "Path to effective mobile advertising in Asian markets." Asia Pacific Journal of Marketing and Logistics, pp. 55-80, 2019. https://doi.org/10.1108/ apjml-06-2017-0112

[6] eMarketer, "Mobile ad spend to top $\$ 100$ billion worldwide in $2016,51 \%$ of digital market" 2016. [Online]. Available www.emarketer.com/Article/Mobile-Ad-Spend-Top-100-BillionWorldwide-2016-51-of-Digital-market/1012299\#sthash.tNeT5yLo.dpuf [Accessed on 1st March, 2020]

[7] Abbasi, Ghazanfar Ali, Yen Nee Goh, and Shaizatulaqma Kamalul Ariffin. "Stimulating Online Buying Behaviour among Millennials in Pakistan: A conceptual model and Research Propositions." Journal of Entrepreneurship, Business and Economics vol. 7, no. 2, pp. 189219, 2019.

[8] Shankar, Venkatesh, Mirella Kleijnen, Suresh Ramanathan, Ross Rizley, Steve Holland, and Shawn Morrissey. "Mobile shopper marketing: Key issues, current insights, and future research avenues." Journal of Interactive Marketing vol. 34, pp. 37-48, 2016.https://doi.org/10 $.1016 /$ j.intmar.2016.03.002

[9] Shankar, Venkatesh, Mirella Kleijnen, Suresh Ramanathan, Ross Rizley, Steve Holland, and Shawn Morrissey. "Mobile shopper marketing: Key issues, current insights, and future research avenues." Journal of Interactive Marketing vol. 34, pp. 37-48, 2016. https://doi.org/10.1016/j.intmar.2016.03.002

[10] Lin, Ching-Wen, Yen-Chung Hsu, and Ching-Yi Lin. "User perception, intention, and attitude on mobile advertising." International Journal of Mobile Communications vol. 15, no. 1, pp. 104-117, 2017 https://doi.org/10.1504/ijmc.2017.080580

[11] Fishbein, Martin, and Icek Ajzen. "Belief, attitude, intention, and behavior: An introduction to theory and research." (1977). 
[12] Ajzen, Icek. "From intentions to actions: A theory of planned behavior." In Action control, pp. 11-39. Springer, Berlin, Heidelberg, 1985. https://doi.org/10.1007/978-3-642-697463_2

[13] Venkatesh, Viswanath, and Fred D. Davis. "A theoretical extension of the technology acceptance model: Four longitudinal field studies." Management science vol. 46, no. 2, pp. 186-204, 2000. https://doi.org/10.1287/mnsc.46.2.186.11926

[14] Yang, Byunghwa, Youngchan Kim, and Changjo Yoo. "The integrated mobile advertising model: The effects of technology-and emotion-based evaluations." Journal of Business Research vol, 66, no. 9, pp. 1345-1352, 2019. https://doi.org/10.1016/j.jbusres. $\underline{2012.02 .035}$

[15] Ducoffe, Robert H. "Advertising value and advertising on the web-Blog@ management." Journal of advertising research vol, 36, no. 5, pp. 21-32, 1996.

[16] Brackett, L. K., \& Carr, B. N. "Cyberspace advertising vs. other media: Consumer vs. mature student attitudes". Journal of advertising research, vol. 41, no. 5, pp. 23-32, 2001. https://doi.org/10.2501/jar-41-5-23-32

[17] Rahi, S., Ghani, M. A., \& Ngah, A. H. "Integration of unified theory of acceptance and use of technology in internet banking adoption setting: Evidence from Pakistan. Technology in Society, vol. 58, pp. 101120, 2019. https://doi.org/10.1016/j.techsoc.2019.03.003

[18] Oliveira, T., Thomas, M., Baptista, G., \& Campos, F. "Mobile payment: Understanding the determinants of customer adoption and intention to recommend the technology. Computers in Human Behavior, vol. 61, pp. 404-414, 2016. https://doi.org/10.1016/j.chb. 2016.03.030

[19] Aslam, B., \& Karjaluoto, H. "Digital advertising around paid spaces, E-advertising industry's revenue engine: A review and research agenda. Telematics and Informatics, vol. 34, no. 8, pp. 1650-1662, 2017 https://doi.org/10.1016/j.tele.2017.07.011

[20] Bellman, S., Johnson, E. J., Kobrin, S. J., \& Lohse, G. L. "International differences in information privacy concerns: A global survey of consumers". The Information Society, vol. 20, no. 5, pp. 313-324, 2004. https://doi.org/10.1080/01972240490507956

[21] Zhang, R., Gao, M., He, X., \& Zhou, A. "Learning user credibility for product ranking. Knowledge and Information Systems, vol. 46, no. 3, pp. 679-705, 2016. https://doi.org/10 $.1007 / \mathrm{s} 10115-015-0880-1$

[22] Hsiao, W. H., \& Chang, T. S. "Understanding consumers' continuance intention towards mobile advertising: a theoretical framework and empirical study". Behaviour \& Information Technology, vol. 33, no. 7, pp. 730-742, 2014. https://doi.org/10.1080/0144929x. $\underline{2013.789081}$

[23] Martínez-Ruiz, M. P., Izquierdo-Yusta, A., Olarte-Pascual, C., \& Reinares-Lara, E. "Do affective variables make a difference in consumers behavior toward mobile advertising?" Frontiers in psychology, vol. 7, 2017. https://doi.org/10.3389/fpsyg.2016.02018

[24] Spatar, D., Kok, O., Basoglu, N., \& Daim, T. "Adoption factors of electronic health record systems" Technology in Society, vol. 58, 101144, 2019. https://doi.org/10.1016/j.techsoc. 2019.101144

[25] Davis, F.D., Bagozzi, R.P., \& Warshaw, P.R. "User Acceptance of Computer Technology: A Comparison of Two Theoretical Models". Management Science, vol. 35, no. 8, pp. 9821003, 1989. https://doi.org/10.1287/mnsc.35.8.982

[26] Al Kurdi, Barween, Muhammad Alshurideh, Said A. Salloum, Zaid Mohammad Obeidat, and Rami Mohammad Al-dweeri. "An Empirical Investigation into Examination of Factors Influencing University Students' Behavior towards Elearning Acceptance Using SEM Approach." International Journal of Interactive Mobile Technologies (iJIM) vol. 14, no. 02, pp. 19-41, 2020. https://doi.org/10.3991/ijim.v14i02.11115 
[27] Al-Maroof, R. S., Salloum, S. A., AlHamadand, A. Q., \& Shaalan, K. "Understanding an Extension Technology Acceptance Model of Google Translation: A Multi-Cultural Study in United Arab Emirates". International Journal of Interactive Mobile Technologies (iJIM), vol. 14, no. 03, pp, 157-178, 2020. https://doi.org/10.3991/ijim.v14i03.11110

[28] Wei, N. T., Baharudin, A. S., Hussein, L. A., \& Hilmi, M. F. "Factors Affecting User's Intention to Adopt Smart Home in Malaysia". International Journal of Interactive Mobile Technologies (iJIM), vol. 13, no. 12, pp. 39-54, 2019. https://doi.org/10.3991/ijim. v13i12.11083

[29] Moon, M. A., Farooq, A., \& Abbasi, G. A. “3G/4G Mobile Network Band Wagon in Pakistan: A Mixed Method Inquiry into Consumer Adoption Attitude". University of Wah Journal of Management Sciences, vol. 17, 2018.

[30] Ünal, S., Erciş, A., \& Keser, E. "Attitudes towards mMobile advertising - A research to determine the differences between the attitudes of youth and adults". Procedia Social and Behavioural Sciences, vol. 24, pp. 361-377, 2011. https://doi.org/10.1016/j.sbspro. 2011.09.067

[31] Muk, A., \& Chung, C. (2014). Applying the technology acceptance model in a two-country study of SMS advertising, Journal of Business Research (2014), https://doi.org/10. 1016/j.jbusres.2014.06.001

[32] Kim, Y.J., \& Han, J.Y. "Why smartphone advertising attracts customers: A model of Web advertising, flow, and personalization. Computers in Human Behaviour, vol. 33, pp. 256269, 2014. https://doi.org/10.1016/j.chb.2014.01.015

[33] Lee, C., Hsieh, M., \& Huang, H. "The Influence of Mobile Self-efficacy on Attitude towards Mobile Advertising. Advances in Information Sciences and Service Sciences, vol. 3, no 3, pp. 100-108, 2011 https://doi.org/10.4156/aiss.vol3.issue3.13

[34] Bakar, M.S.A. \& Bidin, R. "Technology acceptance and purchase intention towards movie mobile advertising among youth in Malaysia. Procedia-Social and Behavioural Sciences, vol. `130, pp. 558-567, 2014. https://doi.org/10.1016/j.sbspro.2014.04.065

[35] Aydin, G., \& Karamehmet, B. "A comparative study on attitudes towards SMS advertising and mobile application advertising. International Journal of Mobile Communications,vol. 15, no. 5, pp, 514-536, 2017. https://doi.org/10.1504/ijmc.2017.086366

[36] Hausman, A. V., \& Siekpe, J. S. "The effect of web interface features on consumer online purchase intentions". Journal of business research, vol. 62, no. 1, pp. 5-13, 2009. https://doi.org/10.1016/j.jbusres.2008.01.018

[37] Richard, J. E., \& Meuli, P. G. "Exploring and modelling digital natives' intention to use permission-based location-aware mobile advertising". Journal of Marketing Management, vol. 29, no. 5-6, pp. 698-719, 2013. https://doi.org/10.1080/0267257x.2013. $\underline{770051}$

[38] Noor, M.N.M., Sreenivasan, J., \& Ismail, H. "Malaysian consumers attitude towards mobile advertising, the role of permission and its impact on purchase intention: A structural equation modeling approach". Asian Social Science, vol. 9, no. 5, pp. 135-153, 2013. https://doi.org/10.5539/ass.v9n5p135

[39] Liu, C.-L. E., Sinkovics, R. R., Pezderka, N., \& Haghirian, P. "Determinants of consumer perceptions toward mobile advertising - A comparison between Japan and Austria". Journal of Interactive Marketing, vol. 26, no. 1, pp. 21-32, 2012. https://doi.org/10.1016/j.intmar .2011 .07 .002

[40] Podsakoff, Philip M., Scott B. MacKenzie, and Nathan P. Podsakoff. "Sources of method bias in social science research and recommendations on how to control it." Annual review of psychology vol. 63, pp 539-569, 2012. https://doi.org/10.1146/annurev-psych-120710$\underline{100452}$ 
[41] Hair, J. F., Risher, J. J., Sarstedt, M., \& Ringle, C. M. "When to use and how to report the results of PLS-SEM". European Business Review, vol. 31, no. 1, pp. 2-24. https://doi.org/10.1108/ebr-11-2018-0203

[42] Henseler, J., Ringle, C. M., \& Sarstedt, M. "A new criterion for assessing discriminant validity in variance-based structural equation modeling2. Journal of the academy of marketing science, vol. 43, no. 1, pp. 115-135, 2015. https://doi.org/10.1007/s11747-014-0403-8

[43] Cohen, Jacob. Statistical power analysis for the behavioral sciences. Academic press, 2013.

[44] Fornell, C. \& Cha, J. "Partial least squares, in: R. P. Bagozzi (Ed.) Advanced Methods of Marketing Research Cambridge, MA: Blackwell Pubslishers, 1994.

[45] Leong, L. Y., Hew, T. S., Ooi, K. B., Lee, V. H., \& Hew, J. J. A hybrid SEM-neural network analysis of social media addiction. Expert Systems with Applications, vol. 133, pp. 296-316, 2019. https://doi.org/10.1016/j.eswa.2019.05.024

[46] Ooi, K. B., Hew, J. J., \& Lee, V. H. "Could the mobile and social perspectives of mobile social learning platforms motivate learners to learn continuously? Computers \& Education, vol. 120, pp. 127-145, 2018. https://doi.org/10.1016/j.compedu.2018.01.017

[47] Abbasi, G.A., Yow, BC., \& Goh, Y-N. "Does the milk powder scare matter? A survey examining Penang's consumer purchase intention with attitude as the mediator. International Food Research Journal, 27(2), 327-338, 2020.

\section{Authors}

Ghazanfar Ali Abbasi is a PhD candidate and graduate research assistant (Marketing) at Graduate School of Business, Universiti Sains Malaysia. He received his bachelors and master's degree in United Kingdom and Pakistan respectively. He has published in indexed journals i.e. International Food Research Journal, Journal of Entrepreneurship, Business and Economics and International Journal of Electronic Commerce Studies. His research interest includes consumer research information management field, such as online user behavior and decision, electronic commerce, e-business, human-computer interaction, social media adoption and addiction, e-wallet. Email: ghazanfar.abbasi@hotmail.co.uk. ORCID ID: 0000-0003-0748-8996

Su-Yee Sea is an MBA student at Graduate School of Business, Universiti Sains Malaysia. Email: seasuyee@gmail.com

Goh Yen-Nee is serving as a Senior Lecturer at Graduate School of Business, Universiti Sains Malaysia. She received her Doctoral degree in Business Administration from GSB, Universiti Sains Malaysia. Her current research interests include consumer behaviour and tourism marketing. She has published several articles in indexed journals. Email: yngoh@usm.my

Article submitted 2020-04-17. Resubmitted 2020-05-22. Final acceptance 2020-05-24. Final version published as submitted by the authors. 